\section{Pembelajaran Arthropoda Menggunakan Booklet Sebagai Sumber Belajar Mandiri Siswa Kelas X SMA/MA}

\author{
Fadil Muhammad \\ Muhiddin P. \\ Adnan
}

\begin{abstract}
Abstrak. Penelitian ini bertujuan untuk mengembangkan media pembelajaran yang dapat dijadikan sumber belajar alternatif berupa booklet pada pokok bahasan dunia hewan sub bab arthropoda, penelitian ini merupakan penelitian pengembangan research and development (R\&D) menggunakan model ADDIE untuk uji kevalidan media dan materi berdasarkan hasil penilaian dari 2 validator ahli, sedangkan uji kepraktisan dilakukan guru dan siswa terhadap penggunaan media. Tahap pengembangan dilakukan dengan cara validasi booklet, kemudian di implementasikan di SMAN 5 Jeneponto kelas X MIA $A_{3}$ dengan subjek penelitian adalah 35 siswa. Teknik pengumpulan data yang digunakan adalah observasi, wawancara, dan angket. Hasil penelitian menunjukkan hasil uji validitas dengan rata-rata persentase kelayakan media sebesar $85 \%$. Sedangkan kelayakan materi dengan persentase keseluruhan yaitu 86\%, keduanya berada pada kategori sangat layak. Adapun hasil uji coba lapangan pada respon guru dan siswa diperoleh nilai keseluruhan 91\% dari respon guru dan uji coba siswa diperoleh nilai 89,2\%, keduanya berada pada kategori respon sangat positif. Dari penilaian kelayakan yang ditinjau berdasarkan validitas dan kepraktisan dapat disimpulkan bahwa booklet sebagai sumber belajar bersifat valid dan praktis.

Kata Kunci: booklet, interaktif, kevalidan, kepraktisan, arthropoda.
\end{abstract}

\section{Pendahuluan}

Pendidikan berkembang mengikuti perubahan zaman. Perubahan ini menjadi kendali pendidikan. Perkembangan ilmu pengetahuan dan teknologi memberikan pengaruh terhadap proses pendidikan dan pengajaran. Proses pendidikan dan pengajaran harus selalu diselaraskan dengan perkembangan ilmu pengetahuan dan teknologi sesuai dengan tujuan yang hendak dicapai agar dapat diperoleh hasil yang optimal.

Dalam hal ini, lembaga pendidikan perlu menyediakan, mengembangkan serta memanfaatkan aneka sumber belajar mulai dari yang paling sederhana sampai yang berbasis teknologi maju.

Sumber belajar sebagai salah satu komponen pembelajaran dapat diartikan sebagai semua sarana pengajaran yang menyampaikan pesan secara edukatif baik visual maupun audiovisual. Menurut Haryono (2006) pembelajaran sebagai suatu proses kegiatan yang melibatkan berbagai komponen, antara lain pendidik (guru), peserta didik (siswa), materi, metode, sumber belajar, media pembelajaran dan penilaian.

Komponen sumber belajar sangat terikat terhadap proses pembelajaran. Sumber belajar memberikan kesempatan kepada siswa untuk mendapatkan pengetahuan dan informasi secara luas tidak hanya melalui proses pembelajaran yang berlangsung di dalam kelas antara guru

\section{Biology Teaching and Learning}

ISSN 2621 - 5527

Abstract. This Research and Development ( $R$ and $D$ ) concerns on learning media development that can be used as an alternative learning source of booklet on the subject of animal world sub chapter arthropoda. The R and D's model used Analyze, Design, Develop, Implement, Evaluate (ADDIE). Validity test obtained from two expert validators and Practicality test obtained from the using of media by teacher and students.

The Develop stage of this study conducted by validating e-magazine for further be implemented on SMAN 5 Jeneponto, Class of X MIA3. The number of subjects comprised of 35 students. Data collected from interview, observation and questionnaire. The result of validity test showed the average of media feasibility percentage is $85 \%$. While the subject matter feasibility gained $86 \%$. Both of these result showed very decent category which was meant that the media is feasible to be used. The average of teacher and students respond gained 91\% and $89,2 \%$ respectively toward positive respond. From the point of feasibility which had been evaluated by validity and practical test, this study can

be conclude that booklet is valid and practice learning media to be implemented in learning process. Keywords: booklet, interactive, validity, practicality, arthropoda.

Fadil Muhammad

Universitas Negeri Makassar Indonesia

Muhiddin P.

Universitas Negeri Makassar Indonesia

Adnan

Universitas Negeri Makassar Indonesia 
dan siswa.

Sumber belajar adalah segala sesuatu atau daya yang dapat dimanfaatkan oleh tenaga pengajar dan peserta didik, baik secara terpisah maupun dalam bentuk gabungan untuk kepentingan kegiatan pembelajaran dengan tujuan untuk meningkatkan efektivitas, efisiensi, mudah dan menyenangkan untuk kelangsungan pembelajaran (Abdullah, 2012).

Salah satu sumber belajar yang dapat digunakan oleh siswa untuk keperluan belajar mandiri yaitu media cetak. Guru tidak lagi menggunakan model pembelajaran konvesional dimana guru sebagai sumber belajar itu sendiri. Guru dituntut unutk mampu mengarahkan proses pembelajaran menjadi lebih aktif dengan memanfaatkan teknologi informasi dan komunikasi untuk mengembangkan sumber belajar yang mampu mengaktifkan siswa dalam proses pembelajaran. Sumber belajar dapat membantu siswa untuk belajar, baik di dalam kelas maupun di luar kelas.

Namun, sumber belajar mandiri berupa media cetak saat ini belum bervariasi dan inovasinya belum mampu menarik perhatian bagi siswa. Sumber belajar yang digunakan saat proses pembelajaran itu masih menjadikan guru sebagai sumber utamanya meskipun tekadang menggunakan buku paket, dan tidak adanya sumber lain yang bisa digunakan oleh siswa untuk mengembangakan pengetahuan dan potensi-potensinya.

Salah satu media yang dapat dijadikan sumber belajar alternatif yang mendukung dalam kegiatan pembelajaran yakni booklet. Booklet adalah buku kecil yang berfungsi sebagai selebaran untuk menyampaikan pesan-pesan atau informasi-informasi. Booklet merupakan salah satu media cetak untuk menyampaikan pesan-pesan dalam bentuk ringkasan dan gambar yang menarik. Berdasarkan analisis diatas, maka peneliti tertarik untuk mela-kukan penelitian mengenai "pembelajaran arthropoda menggunakan booklet sebagai sumber belajar mandiri siswa kelas X SMA/MA".

\section{Metode Penelitian}

Jenis penelitian yang digunakan adalah research and development dengan model ADDIE yang bertujuan menghasilkan sumber belajar mandiri berupa booklet yang bersifat valid dan praktis. Penelitian ini dilaksanakan pada bulan September 2017 - Juni 2018. Model ADDIE terdiri dari 5 tahap, yaitu analyze (analisis), design (desain), develop (pengembangan), implement (implementasi), dan Evaluate (evaluasi). Penelitian dilakukan dengan pemberian lembar instrumen ke 2 validator, serta guru dan siswa. Instrumen yang telah diisi kemudian dianalisis dengan teknik analisis data deskriptif yang selanjutnya akan ditentukan hasil penelitian berdasarkan tabel berikut:

Tabel 1. Kategori Kevalidan Media dan Materi

\begin{tabular}{|c|c|}
\hline Nilai & Keterangan \\
\hline $1 \leq \mathrm{Va}<2$ & Tidak Valid \\
\hline $2 \leq \mathrm{Va}<3$ & Kurang Valid \\
\hline $3 \leq \mathrm{Va}<4$ & Cukup Valid \\
\hline $4 \leq \mathrm{Va} \leq 5$ & Valid \\
\hline $\mathrm{Va}=5$ & Sangat Valid \\
\hline
\end{tabular}

Ket: Va adalah nilai rata-rata kevalidan dari semua validator.

Tabel 2. Skala Tingkat Penilaian Validator Terhadap Media dan Materi

\begin{tabular}{|c|c|}
\hline Persentase (\%) & Keterangan \\
\hline $70,00-90,00$ & Valid/ Layak \\
\hline $50,00-69,99$ & Valid/Cukup Layak \\
\hline $40,00-49,99$ & $\begin{array}{l}\text { KurangValid / } \\
\text { Kurang Layak }\end{array}$ \\
\hline $0-39,99$ & Tidak Baik (Diganti) \\
\hline
\end{tabular}


Tabel 3. Kategori Kepraktisan Guru dan Siswa

\begin{tabular}{|c|c|}
\hline Nilai & Keterangan \\
\hline $85 \% \leq \mathrm{RS}$ & Sangat Positif \\
\hline $70 \% \leq \mathrm{RS}<85 \%$ & Positif \\
\hline $50 \% \leq \mathrm{RS}<70 \%$ & Kurang Positif \\
\hline $\mathrm{RS}<50 \%$ & Tidak Positif \\
\hline
\end{tabular}

Keterangan: RS adalah rata-rata skor.

Setelah mengetahui persen-tase setiap aspek, selanjutnya dilakukan pengkategorian respon guru dan siswa. Analisis data penilaian dikatakan praktis apabila hasil persentase keseluruhan berada pada kategori positif dan sangat positif. Penilaian dikatakan tidak praktis apabila analisis data penilaian berada pada kategori tidak positif.

\section{Hasil Penelitian}

Pengembangan booklet sebagai sumber belajar mandiri pada materi arthropoda kelas X ini menggunakan jenis penelitian research and development research and development yang mengacu pada model pengembangan ADDIE. Model ADDIE terdiri dari 5 tahap yaitu analyze (analisis), design (desain), develop (pengembangan), implement (implementasi), dan Evaluate (evaluasi). Setelah tahap pengem-bangan media, selanjutnya dilakukan penilaian terhadap media oleh validator serta respon guru dan Siswa. Berikut hasil penilaian validator untuk media dan materi serta respon guru dan siswa untuk uji kepraktisan.

Tabel 4. Skala Persentase Penilaian Media Dari Dua Validator

\begin{tabular}{|l|l|c|c|c|c|}
\hline \multirow{2}{*}{ No } & \multirow{2}{*}{ Kriteria } & \multicolumn{2}{|c|}{ Persentase \% } & \multirow{2}{*}{$\begin{array}{c}\text { Rata-rata } \\
\text { \% }\end{array}$} & \multirow{2}{*}{ Ket. } \\
\cline { 3 - 4 } & & Val.I & Val. II & 90 & Baik / Valid \\
\hline 1 & Komposisi Penulisan & 80 & 100 & 80 & Baik / Valid \\
\hline 2 & Tampilan & 70 & 90 & 87 & Baik / Valid \\
\hline 3 & Kelayakan fitur tambahan & 80 & 93 & 85 & Baik / Valid \\
\hline \multicolumn{2}{|r|}{ Rata-rata Keseluruhan }
\end{tabular}

Tabel 5. Skala Persentasi Penilaian Materi Dari Kedua Materi

\begin{tabular}{|c|c|c|c|c|c|}
\hline \multirow{2}{*}{ No } & \multirow{2}{*}{ Kriteria } & \multicolumn{2}{|c|}{ Persentase \% } & \multirow{2}{*}{$\begin{array}{c}\text { Rata-rata } \\
\mathbf{\%}\end{array}$} & \multirow{2}{*}{ Ket. } \\
\hline & Val.I & Val.II & 82,5 & 1 \\
\hline 2 & Penyajian materi & 80 & 82,5 & 86,5 & 2 \\
\hline 3 & Kebahasaan & 93 & 80 & 90 & 3 \\
\hline \multicolumn{2}{|r|}{$\begin{array}{c}\text { Kesesuaian tingkat } \\
\text { berpikir siswa }\end{array}$} & 100 & 80 & 86 & Baik / Valid \\
\hline
\end{tabular}

Tabel 6. Analisis Data Persentase Respon Guru

\begin{tabular}{|c|c|c|c|}
\hline No & Indikator Pernyataan & Persentase Indikator (\%) & Keterangan \\
\hline 1 & Cakupan materi & 90,5 & Sangat Positif \\
\hline 2 & Penyajian & 90 & Sangat Positif \\
\hline 3 & Kebahasan & 88 & Sangat Positif \\
\hline 4 & Desain grafis & 89 & Sangat Positif \\
\hline \multicolumn{2}{|c|}{ Skor Penilaian Keseluruhan } & $89,2 \%$ & Sangat Positif \\
\hline
\end{tabular}


Tabel 7. Analisis Data Persentase Setiap Indikator Pernyataan Respon Siswa

\begin{tabular}{|c|c|c|c|}
\hline No & Indikator & Persentase Indikator (\%) & Keterangan \\
\hline 1 & Cakupan materi & 100 & Sangat Positif \\
\hline 2 & Keakuratan materi & 88 & Sangat Positif \\
\hline 3 & Kemutakhiran materi & 95 & Sangat Positif \\
\hline 4 & Wawasan & 80 & Positif \\
\hline 5 & Tampilan fisik & 85 & Positif \\
\hline 6 & Kriteria penulisan & 94 & Sangat Positif \\
\hline \multicolumn{2}{|c|}{ Skor Penilaian Keseluruhan } & 91 & Sangat Positif \\
\hline
\end{tabular}

\section{Pembahasan}

Penggunaan media pembelajaran dapat membangkitkan minat, motivasi dan rangsangan dalam proses pembelajaran, sehingga sangat membantu dalam penyampaian pesan kepada siswa (Wiratmojo, P dan Sasonohardjo, 2002). Oleh karena itu, penelitian ini bertujuan untuk mengembangkan media sebagai sumber belajar mandiri siswa. Dalam kegiatan pembelajaran diupayakan siswa menjadi pemeran utama yang aktif, kreatif dan berhasil mencapai tujuan pembelajaran. Sesuai dengan cirinya, setiap pendekatan pembelajaran memerlukan sumber belajar agar penerapannya berjalan dengan baik serta mencapai tujuan yang hendak dicapai.

Sumber belajar yang telah dikembangkan, yakni booklet. Booklet arthropoda ini sangat menarik karena tampilan dan isinya yang variatif. Tanpa sumber belajar, seorang guru cenderung berbicara satu arah kepada muridnya. Namun dengan media guru dapat mengatur kelas sehingga tidak hanya guru sendiri yang aktif tetapi juga mampu mengaktifkan siswa (Halipuddin, 2014).

Booklet arthropoda ini di implementasikan kepada guru dan siswa SMAN 5 Jeneponto. Booklet ini sangat membantu dalam proses pembelajaran arthropoda karena penggunaannya yang praktis dan dapat membangkitkan motivasi dan minat siswa, hal ini dapat diketahui berdasarkan hasil kevalidan dan kepraktisan media pembelajaran dilihat dari hasil analisis data kevalidan dan hasil analisis respon guru dan respon siswa. Validasi booklet ini dilaku-kan oleh 2 validator dengan cara melihat dan menilai produk yang telah dibuat, selanjutnya memberikan nilai pada instrumen lembar validasi yang sebelumnya juga telah divalidasi oleh 2 orang validator. Kevalidan media menyatakan produk siap untuk dimple-mentasikan pada subjek penelitian. Berdasarkan hasil analisis data kevalidan, diperoleh nilai kevalidan untuk setiap aspek yakni $85 \%$ dengan kategori valid. Menurut Suherman (2009), pembelajaran menggunakan media akan lebih menarik perhatian siswa, kejelasan dan daya tarik gambar menimbulkan rasa keingintahuan siswa lebih tinggi, hal yang menunjukkan bahwa media memiliki aspek motivasi dan meningkatkan minat. Validasi materi dilakukan dengan mengacu pada tiga kriteria, dengan persentase keseluruhan media yaitu $86 \%$ dengan kategori valid. Berdasarkan hasil analisis uji respon guru yang telah dilakukan, dengan enam indikator skor keseluruhan respon guru terhadap media yakni 91\% dengan kategori sangat positif. Adapun penilaian respon siswa, dengan empat indikator secara keselurahan 89,2\% menunjukkan kategori sangat positif.

\section{Kesimpulan}

Berdasarkan hasil penelitian dari analisis data dan pembahasan maka dapat disimpulkan bahwa pembelajaran arthropoda menggunakan booklet sangat membantu berdasarkan hasil analisis kevalidan dan hasil analisis kepraktisan. Sumber belajar yang dikembangkan bersifat valid berdasarkan penilaian ahli media dan ahli materi. Nilai kevalidan untuk media adalah $85 \%$ dengan kategori valid, sedangkan untuk nilai kevalidan untuk validasi materi adalah $86 \%$ dengan kategori valid. Kepraktisan sumber belajar yang dinilai berdasarkan respon guru dan respon siswa berada pada kategori positif, masing - masing persentase respon guru $91 \%$ dan respon siswa 89,2 \%. 


\section{Referensi}

Adipurnomo, Haryono. (2006). Sumber dan Media Pembelajaran. Malang: DEPDIKNAS Direktorat Jenderal Peningkatan Mutu Pendidikan dan Tenaga Kependidikan.

Abdullah, Ramli. (2012). Pembelajaran Berbasis Pemanfaatan Sumber Belajar. Jurnal Ilmiah DIDAKTIKA. XII (2), 216-231.

Suherman, Y. (2009). Pengembangan Media Pembelajaran Bagi ABK. Diklat Profesi Guru PLB Wilayah X Jawa Barat.

Wiratmojo,P \& Sasonohardjo, (2002). Media Pembelajaran Bahan Ajar Diklat Kewidyaiswaraan Berjen-jang Tingkat Pertama, Lembaga Administrasi Negara.

\begin{tabular}{|l|l|}
\hline Fadil Muhammad & $\begin{array}{l}\text { S, Pd. Jurusan Biologi FMIPA UNM, Universitas Negeri Makassar. } \\
\text { Email: vadjil50@gmail.com }\end{array}$ \\
\hline Muhiddin P. & $\begin{array}{l}\text { S,Pd, M, Pd, Dr. Dosen. Jurusan Biologi FMIPA UNM, Universitas Negeri } \\
\text { Makassar. } \\
\text { Email: muhiddin.p@unm.ac.id }\end{array}$ \\
\hline Adnan & $\begin{array}{l}\text { M, S. Dr. Dosen. Jurusan Biologi FMIPA UNM, Universitas Negeri } \\
\text { Makassar. } \\
\text { Email: adnan unm@yahoo.co.id }\end{array}$ \\
\hline
\end{tabular}

